Journal of Social Sciences 4 (3): 216-221, 2008

ISSN 1549-3652

(C) 2008 Science Publications

\title{
The Random Walk Hypothesis for the Zimbabwe Stock Exchange: January 1998-November 2006
}

\author{
Tafirenyika Sunde and James Zivanomoyo \\ Polytechnic of Namibia, School of Business and Management, Department of Economics, P Bag 13388, \\ Windhoek, Namibia and The Great Zimbabwe State University, Zimbabwe
}

\begin{abstract}
The main intention of this study was to investigate, using monthly data, whether prices in the Zimbabwe Stock Exchange (ZSE) follow a random-walk process as required for there to be market efficiency. The study applied the unit root tests to establish if the ZSE followed a random walk or not. If the ZSE follows a random walk it is said to be efficient and therefore managers of companies and investment specialists cannot take advantage of it to make unnecessarily huge profits. The ZSE was chosen because it represents a typical emerging stock market in Sub-Saharan Africa. The study used the Augmented-Dickey Fuller (ADF) tests with a lag length that was necessary to remove autocorrelation from residuals. Using monthly data from January 1998-November 2006 we found that the ZSE did not follow a random walk and therefore was not efficient in the weak form. This meant that past prices had an influence in the determination of future prices and this provided an opportunity for out-performance by skillful financial managers and investment specialists. During the period studied investment analysts and managers of companies were able to take advantage of these investment opportunities to make abnormal returns from the ZSE. The current study helped to corroborate the findings of a similar previous study that was carried out on the Zimbabwean economy for the period $1990-1998^{[8]}$.
\end{abstract}

Key words: Stock market efficiency, trend and drift analysis

\section{INTRODUCTION}

The increasing prominence of the stock market in Zimbabwe is one of the most striking features of financial development over the last decade. The successful functioning of an economy demands the mobilization of all capital resources available and their productive utilization in the development of all sectors of the economy. The Zimbabwe Stock Exchange (ZSE) plays an essential role in raising capital funds and also as a link between firms and the investing public.

An efficient market is one in which changes in information about the prospects of a given security are immediately reflected in the stock's price. Any information that could be used to predict stock performance should be reflected in the stock prices. As soon as there is any information indicating that a stock is under-priced and therefore offers a profit opportunity, investors flock to buy the stock and immediately bid up the price to a fair level, where only ordinary rates of return can be expected. These ordinary rates of return are simply rates of return commensurate with the risk of the stock. However, if prices are bid immediately to fair levels, given all available information, it must be that they increase or decrease only in response to new information. New information by definition must be unpredictable, if it could be predicted, then the prediction would be part of today's information. Thus stock prices that change in response to new unpredictable information must also move unpredictably.

There are three types of market efficiency, the weak form, semi-strong and the strong market efficiency ${ }^{[2,3,5,10]}$. The weak form asserts that all past market prices and data are fully reflected in securities prices. In other words, technical analysis to try and take advantage of the market is of no use. The semi-strong form asserts that all publicly available information is fully reflected in securities prices. The strong form asserts that all information is fully reflected in securities prices. In other words, even insider information is of no use because the market is unbeatable.

The Zimbabwe Stock Exchange (ZSE) was established in 1896, although the current ZSE's

Corresponding Author: Tafirenyika Sunde, Polytechnic of Namibia, School of Business and Management, Department of Economics, P, O Box 26925, Windhoek, Namibia. Tel: +264-61-2072406. Fax: +264-61-207 2442. Mobile: 00264813711879 
uninterrupted operations date back only to 1946 . It is the second largest in sub-Saharan Africa after the Johannesburg Stock Exchange. The fastest growth of the ZSE occurred between 1994 and 1996, with capitalization rising at an average annual rate of $36 \%$ in US dollar terms ${ }^{[8]}$. There are two indices on the ZSE, viz: the Industrial Index and the Mining Index. In addition, the ZSE has over seventy listed companies trading.

The Zimbabwe stock market was opened to foreign investors in 1993. Foreign presence has increased to such an extent that trading by such investors accounted for $78 \%$ of total trading in the year to March 2000 . However, some restrictions on foreign investors still remain. A single foreign investor is not permitted to own more than $5 \%$ of the shares of a listed company and total foreign ownership is not permitted to exceed $25 \%$ of the shares of a single company. The exact rate of capital gains tax depends on the length of time for which an investment has been held and serves to discourage speculative trading on the market. The increasing activity on the ZSE led to a rise in turnover from Z\$7,653 million in 1990 to over Z\$21 billion in February 2003.

There has been extensive analysis of market efficiency on developed and more established emerging stock markets but the same can not be said for African markets including the Zimbabwean Stock Exchange. This is because many of them are new and small and there has been a problem in obtaining data series of sufficient frequency and duration. In the case of the ZSE, the only financial data which have been readily available since 1980 is the industrial and mining indices. Data on other financial indicators like earnings per share ratio, market capitalization and liquidity ratio were only systematically recorded as from January 1994. This unavailability of financial data made it difficult for one to test the efficiency of the Zimbabwe stock market. In addition, the financial sector was highly regulated prior to the implementation of the International Monetary Fund (IMF) supported Economic Structural Adjustment Programme (ESAP) in 1991, thus making any academic study on the stock market fruitless.

Financial reforms implemented during the early 1990s brought new interest by financial economists to study the efficiency of the ZSE. Because the area of the study is fairly new in the Zimbabwean context, only a few studies were done. One of the previous studies done on Zimbabwe used weekly data commencing from the third week of January 1990 and ending the last week of August $1998^{[8]}$. The current study will differ from this previous study in the sense that it would use monthly rather than weekly data. The current study also covers a different time period, that is, January 1998 to November 2006. It is expected therefore that the current study will bring new understanding and knowledge on the efficiency of the Zimbabwe Stock Exchange. Economic theory says in a perfectly efficient stock market, prices should follow a random walk. Under a random walk, historical data on stock prices and volume of trade have no value in predicting future stock prices $^{[4,5,6,9]}$. In other words, statistical analysis is useless and trying to time the market is a fool's errand. A common test for market efficiency is to establish whether a price follows a random walk-a test that can be applied at the level of individual stocks or market index. If a stock price or market index does follow a random walk, then we can conclude that investors will be unable to consistently earn abnormal returns. This is consistent with the notion that stocks are being appropriately priced at their equilibrium values. If a market does not follow a random walk, then there may be distortions in the pricing of capital and risk, which has implications for the allocation of capital within an economy. The hypothesis to be tested is that in an efficient ZSE market, the industrial index follows a random walk.

\section{REVIEW OF THEORETICAL LITERATURE}

Efficient capital markets are those in which current market prices reflect all available information. This means that current market prices reflect the underlying present value of securities and there is no way to make unusual or excess profits by using the available information. Competition among the many well backed highly paid, aggressive analysts ensures that, as a general rule, stock prices ought to reflect available information regarding their proper levels. In an efficient market, financial managers cannot time issues of bonds and stocks, the issuance of additional stock should not depress the stock's market price, stock and bond prices should not be affected by a firm's choice of accounting method.

The weak-form hypothesis ${ }^{[5,8]}$ : The weak-form hypothesis asserts that stock prices already reflect all information that can be derived by examining market trading data such as the history of past prices, trading volume, or short term interest. This version implies that trend analysis is fruitless. The weak-form hypothesis holds that if such data ever conveyed reliable signals about future performance, all investors already would have learned to exploit the signals. Ultimately, the signals lose their value, as they become widely known 
because a buy signal, for example would result in an immediate price increase.

A capital market is said to be weakly efficient or satisfy weak-form efficiency if it fully incorporates the information in the past stock prices. The weak-form efficiency is represented mathematically as:

$$
\mathrm{Pt}=\mathrm{Pt}-1+\text { Expected return+Random error }
$$

Equation 1 says that the price today is equal to the sum of the last observed price plus the expected return on the stock plus a random component occurring over the interval. The last observed price could have occurred yesterday, last week, or last month, depending one's sampling interval. The expected return is a fraction of a security's risk. The random component is due to new information on the stock. It could be either positive or negative and has an expectation of zero. The random component in any period one period is unrelated to the random component in any past period. Hence, this component is not predictable from past prices. If the stock prices follow Eq. 1, they are said to follow a random walk. Weak-form efficiency is about the weakest type of efficiency that we would expect a financial market to display because historical price information is the easiest kind of information about a stock to acquire. If it were possible to make extraordinary profits simply by finding the patterns in the stock price movements, everyone would do it and any profits would disappear in the scramble. Suppose the price of a stock displays a cyclical pattern, shrewd investors would buy at the low points, forcing those prices up. Conversely, they would sell at sell at high points, forcing prices down, via competition regularities would be eliminated, leaving only random fluctuations.

The semi-strong efficiency ${ }^{[5,8]}$ : A market is semistrong efficient if prices incorporates all publicly available information, including information such as published accounting statements, wire news, announcements as well as historical price information. Fundamentalists use the above information when buying or selling stocks. If fundamental analysis works, the efficient market hypothesis (semi-strong form) is wrong. The distinction between semi-strong efficiency and weak-form efficiency is that semi-strong efficiency implies weak-form efficiency in that semi-strong efficiency requires not only that the market be efficient with respect to historical price information, but all the information available to the public be reflected in price.

The strong-form efficiency ${ }^{[5,8]}$ : This form says that anything that is pertinent to the value of the stock and that is known to at least one investor is in fact, fully incorporated into the stock value. In other words, security prices reflect all available information that is public and private data. A precondition for this strong version of the hypothesis is that information and trading costs, the costs of getting prices to reflect information, are always zero. Its advantage, however, is that it is a clean benchmark that allows to sidestep the problem of deciding what are reasonable information and trading costs. Since there are surely positive information and trading costs, the extreme version of the market efficiency is unattainable. If one can make money by inside trading (assuming that you don't get caught), the strong EMH is wrong, but may be weak or semi-strong EMH is still correct.

There are various methods of testing the random walk model. These include the variance ratio test, the non-parametric runs tests and the unit root tests ${ }^{[2,3,7,10]}$. In this study we used the unit root to tests to test whether the ZSE follow a random walk or not.

\section{MATERIALS AND METHODS}

The data used in this study was obtained from International Finance Corporations Emerging Market Database (IFC-EMDB) and the ZSE. The sample is monthly from January 1998 to November 2006 with 107 observations and contains local currency denominated stock indexes for Zimbabwe. We chose to use the IFC indexes rather than other local stock price indexes only for several reasons. First, these indices are constructed on a consistent basis. Second, these indices include the most actively traded stocks in the Zimbabwean market and cover at least $60 \%$ of market capitalization. Third, the IFC-EMDB has been used in numerous recent studies.

Unit root tests: We examined the weak form efficiency hypothesis using unit root tests derived from previous studies $^{[10]}$. Three models were used (model with both trend and drift, model with drift, and model with neither trend nor drift):

\section{Model 1:}

$\mathrm{P}_{\mathrm{t}}=\beta_{0}+\beta_{1}\left(\mathrm{t}-\frac{\mathrm{T}}{2}\right)+\beta_{2} \mathrm{P}_{\mathrm{t}-1}+\mu_{\mathrm{t}}$

(with trend and drift)

Model 2:

$\mathrm{P}_{\mathrm{t}}=\beta_{0}^{*}+\beta_{2}^{*} \mathrm{P}_{\mathrm{t}-1}+\mu_{\mathrm{t}}^{*}$

(with a drift) 
Model 3:

$$
\begin{aligned}
& \mathrm{P}_{\mathrm{t}}=\beta_{2}^{* * *} \mathrm{P}_{\mathrm{t}-1}+\mu_{\mathrm{t}}^{* *} \\
& \text { (neither trend nor drift) }
\end{aligned}
$$

where: $P_{t}=$ Industrial index series

$\beta_{0}=$ Drift

$\mathrm{T}=$ Total number of observations

$\mu_{\mathrm{t}}=$ Error term

The hypothesis is:

$$
\mathrm{H}_{0}: \alpha=1 \mathrm{H}_{1}: \alpha \neq 1
$$

If the hypothesis of a unit root in the industrial index is rejected, it implies that the consecutive changes in the industrial index over the relevant period are random. Therefore, market index follows a random walk and its movement in any period cannot be predicted from information in the index in any previous period(s) and the market is weak form efficient. Tests for market efficiency are carried out for the industrial stock market that has many diversified counters as opposed to the mining counters.

\section{DISCUSSION OF RESULTS}

In carrying out the unit root tests we used a sequential testing technique that helped to distinguish series that were trend stationery from those that were difference stationary ${ }^{[2,3,7]}$, that is, which of the models 1, 2 or 3 is appropriate (Table 1, 2 and 3). Starting with the general model (model 1) incorporating both trend and drift, we tested the null hypothesis that $\beta_{2}=1$ (that is, there is a unit a unit root and the series is not I (0)). If this is not rejected, we test the null hypothesis that $\beta_{1}=0$ (that is, the trend is insignificant). If that is not rejected, we use simplified model 2 and test the null hypothesis that $\beta_{2}^{*}=1$ If this is not rejected, we use the simplified model 2 and test the null hypothesis that $\beta_{0}^{*}=0$ If this is not rejected, then we use a further simplified Model 3, without trend or drift and test the null hypothesis that $\beta_{2}^{* *}=1$ Using this sequence of tests, it is possible to determine which, if any, of the three possible unit root models are appropriate. If the hypothesis of a unit root (that is, not I (0) was rejected, unit root tests are then carried out on the first differences of the selected model, to determine whether the selected series is I (1) or characterized by a higher order of integration.

Starting with the general model (model 1) incorporating both trend and drift, the null hypothesis is rejected. The coefficient of LINDIN-1 which is close to one indicates that is there is no unit root and the tprobability is significant at $5 \%$. DW is 1.98 indicating that there is no autocorrelation between successive error terms. Using model 1, we can conclude that the Zimbabwe Stock Exchange does not follow a random walk and therefore is not efficient in the weak form. The trend is insignificant and we drop it in our model.

Using a simplified model 2 (with drift and no trend), it can be seen that there is no unit root and the

Table 1: Equation 1 modeling LINDIN by OLS (using data regression modified 2.xls) the estimation sample is: 27-132

\begin{tabular}{llllll}
\hline & Coefficient & Standard Error & t-value & t-probability & Part. ${ }^{2}$ \\
\hline LINDIN $^{-1}$ & 0.965145 & 0.02954 & 32.7 & 0.000 & 0.9120 \\
Constant & 0.274386 & 0.2275 & 1.21 & 0.231 & 0.114 \\
Trend & 0.00148561 & 0.0009310 & 1.60 & \\
Sigma & 0.110079 & RSS & 1.24808389 & & \\
$\mathrm{R}^{2}$ & 0.987715 & $\mathrm{~F}(2,103)$ & $4141[0.000]^{* *}$ & & \\
Log-likelihood & 85.0095 & DW & 1.98 & \\
No. of observations & 106 & no. of parameters & 3 & \\
Mean (LINDIN) & 9.29127 & var (LINDIN) & 0.958424 & & \\
\hline
\end{tabular}

Table 2: Equation 2 modeling LINDIN by OLS (using data regression modified 2.xls) the estimation sample is: 27-132

\begin{tabular}{llllll}
\hline & Coefficient & Standard error & t-value & t-probability & Part. R \\
\hline LINDIN $^{-1}$ & 1.00884 & 0.01117 & 90.3 & 0.000 & 0.9874 \\
Constant & -0.0491961 & 0.1040 & -0.473 & 0.637 & 0.0021 \\
Sigma & 0.110894 & RSS & 1.27893927 & & \\
$\mathrm{R}^{2}$ & 0.987411 & $\mathrm{~F}(1,104)$ & $8157[0.000]^{* *}$ & \\
Log-likelihood & 83.7151 & DW & 2.01 & \\
No. of observations & 106 & No. of parameters & 2 & \\
mean (LINDIN) & 9.29127 & var (LINDIN) & 0.958424 & \\
\hline
\end{tabular}


J. Social Sci., 4 (3): 216-221, 2008

Table 3: Equation 3 modeling LINDIN by OLS (using data regression modified 2.xls) the estimation sample is: 27-132

\begin{tabular}{llllll}
\hline & Coefficient & Standard Error & t-value & t-probability & Part. ${ }^{2}$ \\
\hline LINDIN $^{-1}$ & 1.00358 & 0.001153 & 871 & 0.000 & 0.9999 \\
Sigma & 0.110483 & RSS & 1.28169224 & & \\
Log-likelihood & 83.6012 & DW & 2 & \\
No. of observations & 106 & No. of parameters & 1 & \\
Mean (LINDIN) & 9.29127 & var (LINDIN) & 0.958424 & & \\
\hline
\end{tabular}

t-probability is significant at $5 \%$. The DW is 2 implying that successive error terms are not related. The null hypothesis is rejected and we accept the alternative hypothesis that the ZSE does not follow a random walk and the market is inefficient in the weak form. The constant is insignificant and we therefore drop it in our model. In other words, historical prices of the securities can be used to predict what future prices are likely to be.

Having dropped the constant, we used model three (3), which has neither trend nor drift. The model is significant at $5 \%$ and has no unit root. DW is 2 indicating that successive error terms are not auto correlated. Absence of the unit root means that the ZSE does not follow a random walk and is therefore not efficient in the weak form. It should be noted that the ZSE is a thinly traded market and interpreting the results is made difficult by infrequent trading on the observed index. Thus the rejection of the random walk hypothesis may be a result of the used observed index, which is an imprecise estimate of the true value of the index in the presence of non-synchronous trading.

However, these results are in line with what previous researchers on the Zimbabwean economy found ${ }^{[8,9]}$. These previous researchers used multiple variance tests to examine the random walk hypothesis for eight African stock markets. In seven of these markets, Botswana, Egypt, Kenya, Mauritius, Morocco, Nigeria and Zimbabwe, the hypothesis is rejected because returns are correlated. For South Africa, however, the Johannesburg Stock Exchange all-share index follows a random walk.

\section{CONCLUSION}

The analysis undertaken in this study has shown that past prices have an influence in the determination of the current price. The market is inefficient in the weak form which implies that the ZSE does not follow a random walk. This means that the ZSE provides the opportunity for out-performance by skillful managers and investment specialists. During the period that has been studied, investment analysts and managers who were able to take advantage of these investment opportunities made abnormal returns from the ZSE.
When a market does not follow a random walk it can be taken advantage of, however, in some cases the resultant transactions costs may reduce or eliminate such advantages. Due to the existence of such technical anomalies, financial managers are able to time issue of bonds and stocks to their advantage. It should be noted that issuance of additional stock depresses the stock's market price and also that stock and bond prices are also affected by a firm's choice of the accounting method to use. All this is information that may be exploited to the advantage of the financial managers.

In order to make the ZSE efficient it is recommended that the Zimbabwean authorities should put in place measures and regulations that enable large numbers of well-informed investors. The ZSE should insist on timely release of precise and quality information to boost public and investor confidence and provide a platform for informed decision making by the investing public. The ZSE must apart from the trading floor announcements, find a wider information network to disseminate stock market information. In order to disseminate information instantaneously, the ZSE, should not only use floor trading announcements but should use all available media and means of communication like the internet, print, audio and visual. Efficient media and means of communication would enable investors to react more quickly on any relevant information regarding the purchase or sale of stocks on the ZSE.

As more data become available in future we recommend that studies should be carried out to establish whether the ZSE follow a random walk as the market become more liquid and more institutionally mature. A study that uses weekly or daily data and focusing on individual stocks for all shares market (the industrial market and mining securities market) employing the unit root tests or the variance ratio tests could also be carried out.

\section{REFERENCES}

1. Batool, A., 2008. Testing weak-form efficiency in the Bahrain stock market. International Journal of Emerging Markets, 3: 38-53. DOI: 10.1108/17468800810849213 
2. Dickey, D.A. and W. Fuller, 1981. Likelihood ratio statistics for autoregressive time series with a unit root. Econometrica, 49: 1057-1082. URL: linkinghub.elsevier.com/retrieve/pii/S01677152060 01957

3. Dolado, J.J., T. Jenkinson and S. Sosvilla-Rivero, 1990. Cointegration and unit roots. J. Econ. Surveys, 4: $275-284$. doi: $10.1111 / \mathrm{j} .1468-$ 2257.1991.tb00548.x

4. Fama, E. and K. French, 1988. Permanent and temporary components of stock prices. J. Political Econ.,96:246-273.

portal.acm.org/citation.cfm?id=775582.775591 -

5. Fama, E.F., 1991. Efficient capital markets 2: A review of theory and empirical work. J. Finance, 25:383-417.

www.cfapubs.org/doi/pdf/10.2469/faj.v55.n6.2310

6. Haque, M. Hassan, M.K. and Varela, O. 2001. Stability, volatility, risk premiums and predictability in Latin American Emerging Stock Markets, Quarterly Journal of Business and Economics, $\quad 40(3-4), \quad 23-44$. www.informaworld.com/index/713706246.pdf

7. Karemera, D. Ojah, K. and Cole, J.A. 1999. Random walks and market efficiency tests: Evidence from emerging equity markets, Review of Quantitative finance and Accounting, 13(2), 171-188. www.scielo.br/scielo.php?pid=S1413$80502006000200003 \&$ script=sci_arttext\&tlng=en $42 \mathrm{k}$
8. Jefferis K. R. 1995. The development of stock markets in Sub-Saharan Africa. South African Journal of Economics, Economic Society of South Africa, vol. 63(3). 192- 201 doi:10.1111/j.18136982.1995.tb01241.x

9. Smith, G., K. Jefferis and Keith Ryoo, 2002. African Stock Markets: Multiple Variance Ratio Tests of Random Walks. Applied Financial Economics, Taylor and Francis Journals, Vol. 12(7). $\quad 475-84 . \quad$ doi: $10.1111 / \mathrm{j} .1813-$ 6982.2005.00004.x

10. Smith, Graham, and Ryoo, Hyun-Jung 2003. Variance Ratio Tests of the Random Walk Hypothesis for the European Emerging Stock Markets. The European Journal of Finance, 9(3). 290-300.

www.informaworld.com/smpp/713379362$88352428 /$ title $\sim$ content $=\mathrm{g} 713932861 \sim \mathrm{db}=$ all -

11. Urrutia, J.L., 1995. Tests of random walk and market efficiency for Latin American emerging stock markets. Journal Financial Research., 18, 299-309.

www.informaworld.com/smpp/713379362$88352428 /$ title $\sim$ content $=\mathrm{g} 713932861 \sim \mathrm{db}=$ all - 